\title{
Student Nurses' Attitude Towards Research at Ndola School of Nursing: A Case Scenario for Social Marketing
}

\author{
Article by Vivian Mwiinga \\ Nursing, Texila American University, Zambia \\ Email:-v.mwiinga@yahoo.com
}

\begin{abstract}
This paper evaluates third year student nurses' attitude towards research at Ndola school of nursing. Research has been described as a keystone of service delivery. What is the attitude of student nurses towards research?

Methodology: A non-experimental descriptive cross section study conducted among all (43) third year student nurses between $26^{\text {th }}$ march and $8^{\text {th }}$ April 2015. Convenient sampling was done. Semi-structured questionnaire used. Qualitative and quantitative data analyzed through Content analysis and Epi-data version 3.

Results: Eighty-six percent of the respondents were females, while $14 \%$ were males and $65.9 \%$ were aged $18-30$ years. Findings revealed that $55 \%$ don't like research and $72.7 \%$ had poor attitude. Problems encountered comprised; time consuming 57\%, don't know methodology $18 \%$, difficult 16\%, expensive $7 \%$ and $2 \%$ lacked interest. Additionally, $68 \%$ of respondents would conduct own research and 91\% would utilize other people's findings. However, $75 \%$ have never read a scientific journal. Suggestions are: allocation of more time, simply the content, introduce at degree level, improve access to computers and library at $47.7 \%, 27.2 \%, 13.6 \%, 6.8 \%$ and $4.5 \%$ respectively.

Discussion: Over 50\% of respondents were uninterested in research due to factors like time consuming and minimal knowledge on methodology and poor attitude. However, they showed interest to conduct research at a later stage in their career. Therefore, there is need to employ social marketing strategies in research using public health communication tool.

Conclusion: Student nurses lack interest in research and their attitude is influenced by problems encountered, which should be changed through social marketing of research.
\end{abstract}

Keywords: Interest, Attitude, Student nurses, Challenges, Research

This paper evaluates third year student nurses' attitude towards research at Ndola school of nursing: A case scenario for social marketing. Research is fundamental to evidence based practice. Nursing research is a systematic inquiry designed to develop knowledge about issues of importance to nurses, including nursing practice, nursing education and nursing administration (Polit \& Beck 2006) and research has been incorporated in the curriculum of the trainee nurses. However, most of the students lack interest to undertake research and do not meet the deadlines. What is the attitude of student nurses towards research? Findings will help in designing social messages to address the gap.

Background Information (not requested information given as overview)

\section{Importance of research}

According to Royal College of nursing in Scotland importance of research includes the following:

- Making health and social care more cost effective as it improves productivity and efficiency.

- Helps to improve the health of the people as it improves the practice.

- Supports the delivery of key health outcomes and health inequalities.

- It equips nurses with knowledge and analytical skill they need to make informed decisions and contribute effectively to new developments, from individual improvements in practice to wholesale design of service. 
- Nursing research and evidence implementation are essential parts of the education and training of existing and future nursing workforce and improves the quality of care given to patients and so increases public confidence in health and social care services

Review of literature revealed that there are limited studies that have looked at student nurses' attitude towards research in Zambia and related studies have been done in other countries.

In Thailand a study was conducted among nurses to identify factors influencing research among nurses, findings revealed that only $20 \%$ of the nurses had experience in conducting of research of their own, of these $67.4 \%$ had good attitude towards doing research (Petchnoy \& Salee). Analysis of factors included funding support, availability of research advisors, knowledge of research methodology and attitude towards conducting research were found to be statistically significant and had influence. Another study was conducted by National Nursing council from 1982 1986 reported that $17.5 \%$ research projects were done by nurses from public health (Srisuphan 1996). Lynn documented that nurses who had negative attitude towards conducting research did not do much research. While those that had positive attitude had conducted research before (Poster et al 1992).

A study done in Ghana by Dorothy et al (2013) on student nurse's attitude towards clinical work revealed that $41 \%$ of the respondents reported that students did not show commitment to clinical work. The attitude portrayed by students had an influence on the way the medical and nursing staff related to them.

In Zambia no studies have been done related to student nurses' attitude towards research, hence the need to conduct research.

\section{Social marketing}

Social marketing is the strategy which can be incorporated to device health messages that can help to change student's behavior and attitude. Research should be promoted to students when they just come in first year so that they understand it better. Concepts of social change will focus on cognitive change, action change, behavior change and value change. Therefore research is the strategy that can be used to generate new body of knowledge and innovations when student's attitudes are good towards research. According to communication theory, public health communication can be defined as the scientific development, strategic dissemination, and evaluation of relevant, accurate, accessible, and understandable health information, communicated to and from intended audiences to advance public health (Bernhardt 2004). The national cancer health institute stated that public health communication can increase knowledge and awareness of a health issue, influence perceptions, beliefs and attitudes.

\section{Statement of the problem}

A study done in united states revealed that many nurses have negative attitude towards research and this is mainly due to the manner in which they have been taught (Melnyk 2008) and similar negative attitudes of students to research have been reported by Dyson (1997). Currently there are no studies that have been done in Zambia, hence the need to determine student nurses' attitude towards research at Ndola school of nursing. Majority of the students at Ndola school of nursing don't submit their research within the stipulated time while in training. What is the attitude of student nurses towards research?

\section{Justification of the study}

The study finding will be able to highlight program needs in research, provide strategic direction for future programs by ensuring that best approaches are explored 
and used to refine the implementation process. Also the findings may be incorporated into policy process to ensure that interventions that are effective are implemented through social marketing. At the same time this study will generate first hand data based on lived local experiences and this will strengthen planning and implementation of research at undergraduate level. It is believed that from this project, policy makers like GNC, service providers like lecturers and the student community at large will understand some of these problems, which must be explored, and solutions put in place.

\section{Research objectives}

\section{General objective}

To evaluate third year student nurses' attitude towards research at Ndola school of nursing.

\section{Specific objective}

To identify factors influencing student nurses attitude towards research?

\section{Research question}

What is the attitude of student nurses towards research?

\section{Operational definitions}

Attitude: is an opinion or general feelings or a settled way of thinking about something.

Research: is a way of inquiry to answer a research question.

Student nurse is a trainee nurse who is still undergoing training to become a nurse

\section{Methodology}

This paper evaluates third year student nurses' attitude towards research at Ndola school of nursing: A case scenario for social marketing.

\section{Research design}

A descriptive cross sectional study was conducted at Ndola school of nursing. It is descriptive because it involved description and analysis of researchable objects with no intervention required. It is cross-sectional because the phenomena under study were captured during one data collection period. It also describes what exists about the phenomena and gives a clear picture of the situation on student nurses' attitude towards research.

\section{Research setting}

The study was carried out at Ndola school of nursing which was purposely selected as it has similar characteristics with other Registered Nursing Schools in Copperbelt. This school is based at Ndola Central hospital in copperbelt province of the republic of Zambia. The study was conducted from $26^{\text {th }}$ march to $8^{\text {th }}$ April 2015.

\section{Study population}

The study population comprised of all third year student nurses at Ndola school of nursing (population study). This population has been selected because it is a group that is currently under taking research projects and understands research process, and is able to bring out in-depth information on problems experienced. 


\section{Sample selection}

Convenient sampling method was used as it involved the use of research subjects at the research site and all 43 student nurses were interviewed and the response rate was $100 \%$.

Inclusion criteria: All third year student nurses at Ndola school of nursing in 2015.

Exclusion criteria: All third year student nurses who are not students of Ndola school of nursing in 2015.

\section{Data collection tool}

Semi-Structured questionnaire modified from other research studies on attitude, done by Collins et al 1997. The tool comprised of closed ended questions for quantitative data and open ended questions to obtain in-depth information for qualitative data.

Validity: This study used a semi-structured interview schedule. To ensure validity of data collection tool, pre-testing of the instrument was done at copperbelt nursing polytechnic to ensure clarity, precision and consistency of questions and where necessary adjustments were made on content and sequencing of questions.

Reliability: The tool was modified from other research study questionnaires that had similar methodology like Collins et al 1997. Reliability of the instrument was achieved by conducting a pre-test study in order to test the degree of accuracy with which the tools measured student nurses' attitude towards research. After the evaluations of the pilot test to assess the extent to which the original questionnaire would grant us reliability, the researcher had an opportunity to perfect the questionnaire from the observed reactions of the respondents to the research instrument and their willingness to answer the questions. Deficiencies in the tool were overcomed by making necessary changes where there were gaps. Also use of open ended questions helped to bring out in-depth information so that all issues relating to attitude were discussed. The pilot testing also helped to determine how much time was needed to administer the questionnaire and to analyse it. The lessons learnt from the pre- test, helped the researcher to develop a reliable and locally focussed modified questionnaire.

\section{Data collection technique}

This study used a semi-structured questionnaire to gather information on student nurses' attitude towards research. The Semi-structured interview schedule contained all the study variables on which data was to be collected which included; interest, attitude, challenges and research. The purpose of the study was explained to the participants and permission was sought from them to allow the researcher to conduct the interview. Privacy and confidentiality and anonymity were maintained by not writing names on interview schedule, instead serial numbers were allocated to all participants. Interview lasted for 5 minutes. The questionnaire was self administered to ensure free opinion without external influence. Filled in questionnaires were checked for completeness and put in a lockable bag for privacy.

\section{Sample size}

The sample size was 43 student nurses who are currently in third year at Ndola school of nursing and this was a population study, therefore findings can be generalized. Calculation of sample size not done since it is a population study.

\section{Ethical consideration}

Consent was obtained from respondents and Ndola school of nursing management. Respondents were in a natural setting and hence were not exposed to emotional or physical harm. Confidentiality and anonymity were maintained to all questionnaires 
as their names did not appear; instead the serial numbers were used. Privacy was maintained as all questionnaires were kept under lock and key after each interview.

\section{Dissemination of findings}

The study findings of this project will be disseminated to ministry of health in Zambia

The General nursing council of Zambia and Ndola school of nursing management.

\section{Data presentation and analysis}

The study aimed at evaluating third year student nurses' attitude towards research at Ndola school of nursing: a case scenario for social marketing. A Total of 43 third year student nurses were interviewed and assessed for attitude toward research and there was $100 \%$ response rate. The respondents were third year student nurses who are currently doing research. Findings of the study were based on analysis of data collected from the student nurses. Point prevalence and 95\% confidence interval was set together with estimates. Cut off point for significance was set at 5\%. Statistical significance achieved if $\mathrm{P}$ value is 0.05 or less, thereby rejecting the null hypothesis. The data was sorted out for completeness, categorized and coded. Data was analyzed using Epi Data version 3. The data was analyzed by content analysis, univariate and bivariate analysis. The data was presented using tables, Pie charts and graphs for easy communication.

\section{Demographic data}

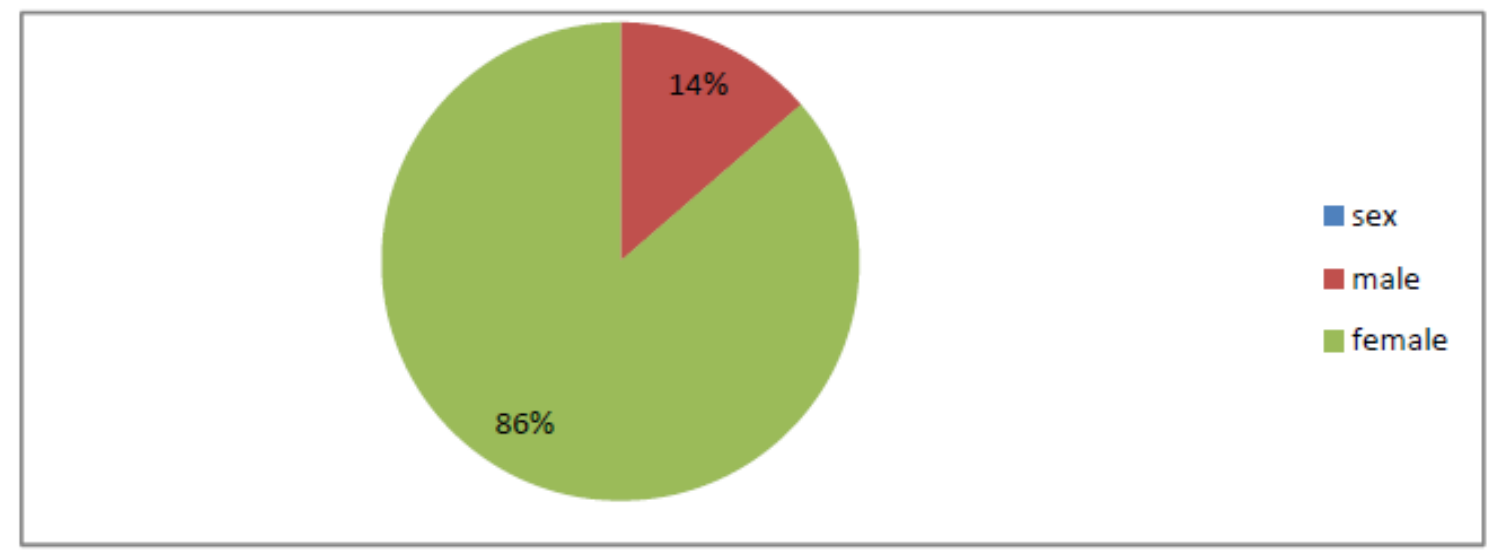

Figure 1. Sex $(n=43)$ This figure shows that majority $(86 \%)$ of the respondents were females, while males accounted $14 \%$

Table 1. Age $(\mathrm{n}=43)$

\begin{tabular}{|l|l|l|l|}
\hline Age & Males & Females & Total \\
\hline $18-30$ & $4(9 \%)$ & $25(56.8 \%)$ & $29(65.9 \%)$ \\
\hline $31-40$ & $1(2 \%)$ & $11(25 \%)$ & $12(27.2 \%)$ \\
\hline $41-50$ & 0 & $2(4.5 \%)$ & $2(4.5 \%)$ \\
\hline Above 51 years & $1(2 \%)$ & 0 & $1(2.2 \%)$ \\
\hline Total & $\mathbf{6 ( 1 3 . 6 \% )}$ & $\mathbf{3 8}(\mathbf{8 6 . 3} \%)$ & $\mathbf{4 4 ( 1 0 0 \% )}$ \\
\hline
\end{tabular}

This table shows that majority $65.9 \%$ of the respondents are aged between $18-30$ years. 
South American Journal of Nursing

Special Edition 2016

\section{Attitude}

Table 2. Do you like research?

\begin{tabular}{|l|l|l|}
\hline Like research & Frequency & Percentage \\
\hline Yes & 20 & $45 \%$ \\
\hline No & 23 & $55 \%$ \\
\hline
\end{tabular}

The above table shows that more than half of the respondents 55\% said they don't like research, while $45 \%$ said that they like research.

Table 3. Attitude towards research

\begin{tabular}{|l|l|l|}
\hline Attitude & Frequency & Percentage \\
\hline Very good & 1 & $2.2 \%$ \\
\hline Good & 5 & $13.6 \%$ \\
\hline Average & 32 & $72.7 \%$ \\
\hline Bad & 3 & $6.8 \%$ \\
\hline Very bad & 2 & $4.5 \%$ \\
\hline Total & $\mathbf{4 3}$ & $\mathbf{1 0 0} \%$ \\
\hline
\end{tabular}

The table shows that majority $72.7 \%$ of the respondents had an average attitude towards research, while $4.5 \%$ said had a very bad attitude.

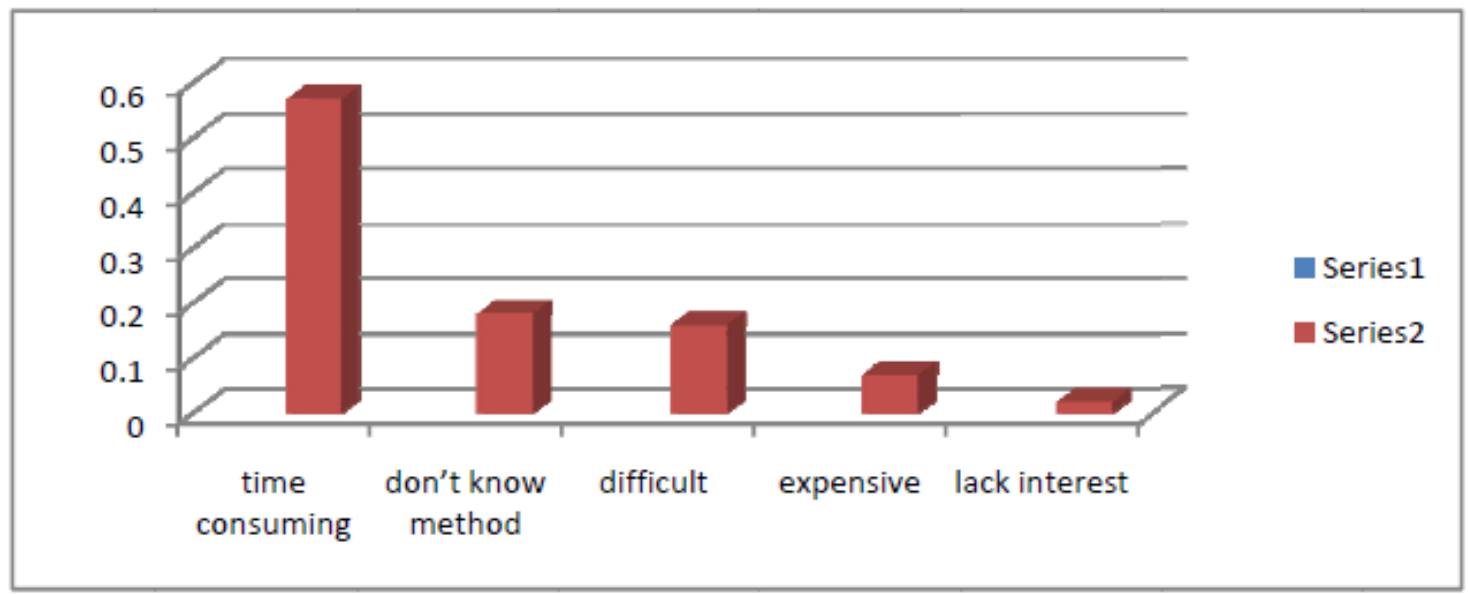

Figure 2. Problems experienced $n=43$

The graph above shows that respondents gave varied reasons $57 \%$ of the respondents said that research was time consuming, 18\% said did not know methodology, $16 \%$ said it was difficult, $7 \%$ said it was expensive and $2 \%$ said lacked interest.

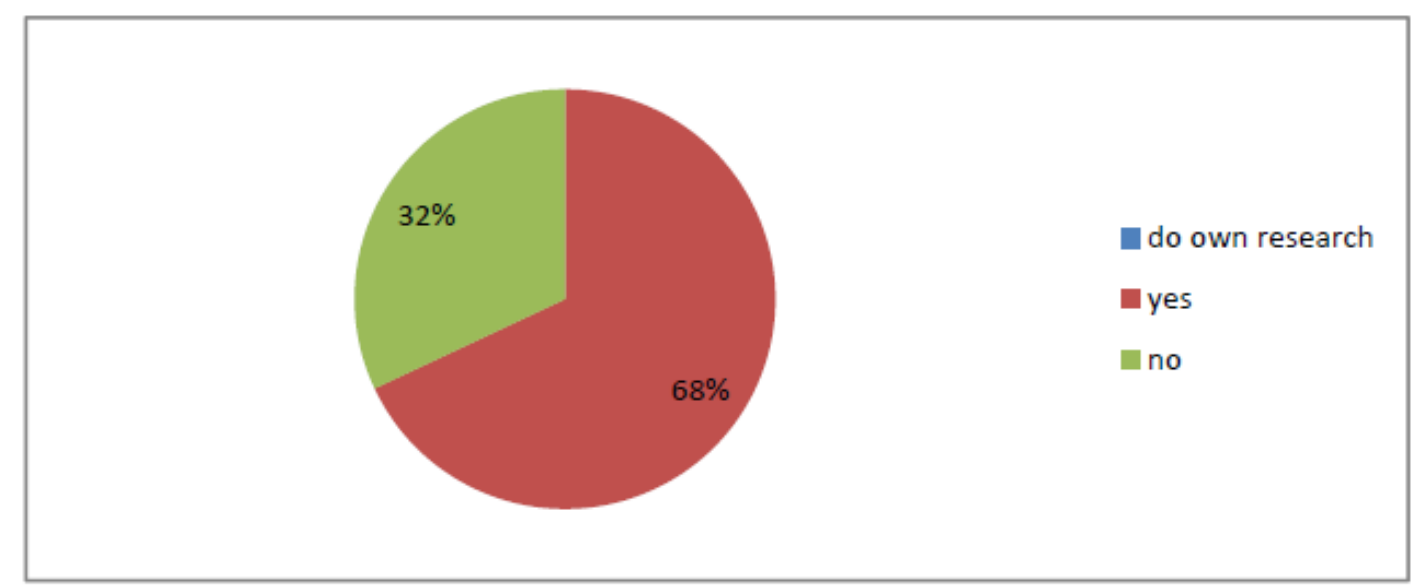

Figure 3. Ability to conduct own Research $(n=43)$

This figure shows that most respondents $68 \%$ said they would conduct own research,

While $32 \%$ said they would not. 


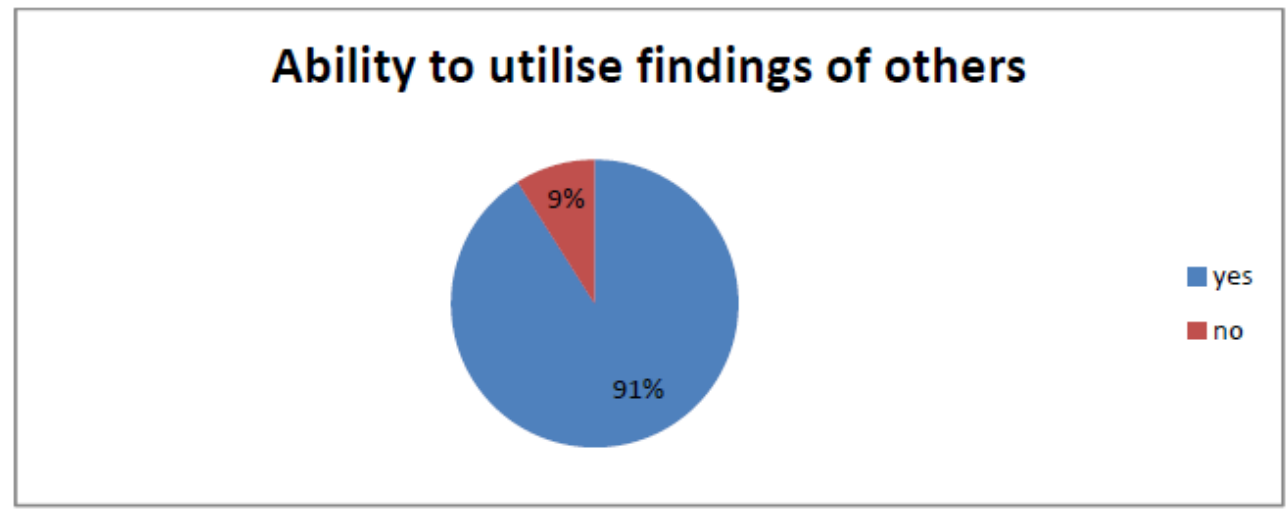

Figure 4. Utilization of findings done by others $(n=43)$

The figure above shows that majority $91 \%$ of the respondents said that they would utilize the findings of other people, while $9 \%$ said they would not.

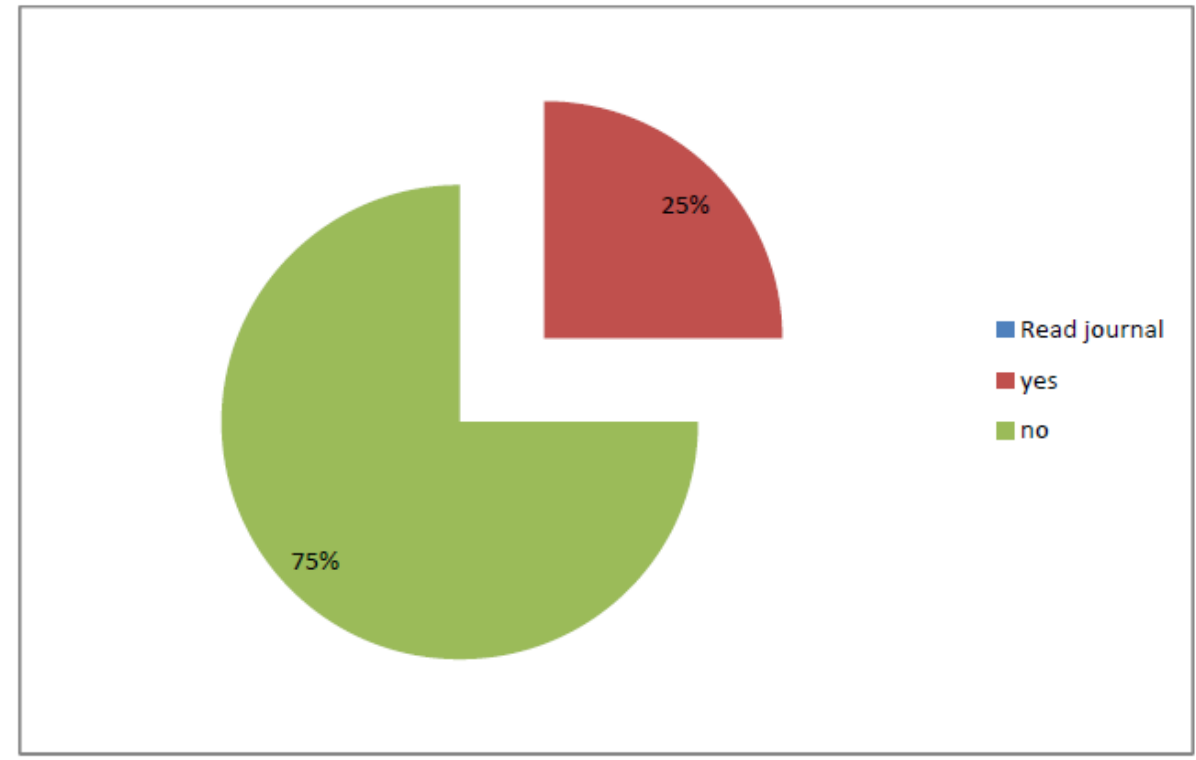

Figure 5. Have you ever read a scientific journal before? $(n=43)$

The above pie chart shows that majority $75 \%$ of the respondents said they have never read a scientific journal, while $25 \%$ said they have read

Table 4. what should be done to improve research at undergraduate level $(n=43)$

\begin{tabular}{|l|l|l|}
\hline Recommendation & Frequency & Percentage \\
\hline $\begin{array}{l}\text { Allocate more time for research \& start in first } \\
\text { year }\end{array}$ & 21 & $47.7 \%$ \\
\hline Simplify content \& methodology & 12 & $27.2 \%$ \\
\hline $\begin{array}{l}\text { Start research at degree level not able to } \\
\text { understand }\end{array}$ & 5 & $13.6 \%$ \\
\hline $\begin{array}{l}\text { Intensify lectures and improve ways of } \\
\text { teaching }\end{array}$ & 2 & $4.5 \%$ \\
\hline $\begin{array}{l}\text { Improve access to computers \& library for } \\
\text { information }\end{array}$ & 3 & $6.8 \%$ \\
\hline Total & $\mathbf{4 3}$ & $\mathbf{1 0 0 \%}$ \\
\hline
\end{tabular}

Table 4 shows that respondents gave varied recommendations and almost half of $47.7 \%$ said should allocate more time for research and should start in first year, $27.2 \%$ said lecturers should simplify content and methodology, $13.6 \%$ said research should start at degree level, $6.8 \%$ said access to computers and library for information should be improved and $4.5 \%$ said teachers should intensify lectures and improve ways of teaching 
South American Journal of Nursing

Special Edition 2016

\section{Discussion of finding}

The study aimed at evaluating third year student nurses' attitude towards research at Ndola school of nursing: a case scenario for social marketing. A Total of 43 third year student nurses were interviewed and assessed for attitude toward research.

The study revealed that majority $86 \%$ of the respondents were females, while males accounted $14 \%$, and majority $65.9 \%$ were aged between $18-30$ years. This could be attributed to the caring attitude of females and nursing was perceived as a job for females and most males shun it.

The findings further revealed that more than half of the respondents $55 \%$ said they don't like research, while $45 \%$ said they like research. These findings compliments the findings for a study done in Canada on medical students which revealed that $24 \%$ had no interest in any research endeavors (Siemens et al 2010). This could be attributed to a lot of factors that impinge on understanding research due to barriers. The study further revealed that majority $72.7 \%$ of the respondents had an average attitude towards research; good attitude accounted $13.6 \%$, while $4.5 \%$ said had a very bad attitude. Findings on negative attitude can be liken to a study done by Lynn \& Laymun (1998) who stated that nurses with negative attitude did not do much research, while the study done in Thailand among nurses revealed that $67.4 \%$ had good attitude towards doing research or had conducted research before (Petchnoy \& Salee: Poster et al 1992). The findings can be likened to a study by Siemens who revealed that Negative attitude of medical students towards research is an obstacle to learning and is associated with poor performance in research.

A study done among nurses in United States revealed negative attitude towards research due to the manner in which they were taught. This shows that exposure to research early acts as a basis for future undertaking of research once one qualifies as a nurse.

The findings further revealed that respondents gave varied reasons on problems experienced towards research and more than half $57 \%$ of the respondents said that research was time consuming, 18\% said did not know methodology, 16\% said it was difficult, $7 \%$ said it was expensive and $2 \%$ said lacked interest.

The findings are comparable to a study done by Akerjordet et al (2012) among clinical nurses who revealed some barriers which include: lack of designated time $60 \%$, interest $31 \%$ and knowledge $31 \%$ and lack of research supervision and support $25 \%$. Research supervision was one of the most significant needs to enhance clinical nurses' research skills, management and organization of research activities $30 \%$. Further studies were done by Siemens et al (2010) among medical students highlighted barrier in research associated to lack of supervision $84.7 \%$, Lack of time $72.3 \%$ and lack of funding $54.1 \%$. Therefore there is need to address these barriers to bring about positive change towards research.

Also the findings revealed that most respondents $68 \%$ said they would conduct their own research, while $32 \%$ said they would not. This compliments the study which was done in Thailand among nurses to identify factors influencing research among nurses, findings which revealed that only $20 \%$ of the nurses had experience in conducting of research of their own. (Petchnoy \& Salee).

The study further revealed that majority $91 \%$ of the respondents said that they would utilize the findings of other people, while $9 \%$ said they would not. This shows that if students are able to read other people's articles, they would also be motivated to undertake research of their own if barriers are addressed. Findings showed that majority $75 \%$ of the respondents said they had never read a scientific journal, while $25 \%$ said they have read. Therefore there is need to encourage and motivate students to participate in research so that they can gain the skill of undertaking research even when they qualify. 
Findings shows that respondents gave varied recommendations and almost half of $47.7 \%$ said should allocate more time for research and should start in first year, $27.2 \%$ said lecturers should simplify content and methodology, $13.6 \%$ said research should start at degree level, 6.8\% said access to computers and library for information should be improved and $4.5 \%$ said teachers should intensify lectures and improve ways of teaching.

\section{Social marketing}

To promote behavior change related to bad attitude towards research, public health communication can be incorporated in the dissemination of information as it can increase knowledge and awareness of health research, influence perceptions, beliefs and attitudes that factor into social norms, illustrate healthy skill, and debunk misconceptions towards research. In view of this I can say that social marketing programs are successful when implemented using research driven process, hence public health communication is a tool which can be used to change student nurses' attitude towards research

\section{Limitation of the study}

Lack of adequate resources such, as funds and the time frame, in which the capstone project was to be completed, were major limitations. Ndola school of nursing has been selected for convenience purposes.

Technological limitation: power outages, limited internet access and network availability.

\section{Strength of the study}

This is a population study and the characteristics of the respondents are similar to those in other registered nursing schools in Zambia and are using the same curriculum, therefore the findings can be generalized. Also the findings will be used to strengthen research and for policy prescription to address challenges experienced by students during research at national level and globally. The findings can be utilized globally as a basis for replication in other countries and has contributed to the body of knowledge.

\section{Conclusion}

Conducting research at undergraduate level is very critical if we are to develop the body of new knowledge that encompass the current health trends and be able to provide quality evidence based care to our patients. More than half of the respondents showed lack of interest in research due to factors like time consuming and minimal knowledge on methodology, difficulty, expensive and poor attitude. However, they showed interest to conduct research at a later stage in their career. Therefore attitude of undergraduate student nurses should be improved towards research as most of them don't like it and had poor reading attitude as shown in the study. The above Challenges must be addressed using Social marketing strategies by using public health communication tool. Research must be promoted as it is the basis to generate new body of knowledge which will improve service delivery based on evidence based practice.

\section{Recommendations}

1. There is need for Nursing Schools and General Nursing Council to utilize social marketing strategies to sensitize students in nursing schools and the public at large to embrace research so that they can come up with health innovation to address current health trends.

2. Need for another study done to assess lecturers /teacher's perception, attitude and practice towards research. 


\section{South American Journal of Nursing}

Special Edition 2016

\section{References}

[1]. Akerjordet, K., Lode, K. \& Severinsson, E. (2012). Clinical nurses' attitudes towards research, management and organisational resources in a university hospital: part 1. Journal of Nursing Management, 20 (6), 814-823.

[2]. Awuah-Peasah Dorothy, Akuamoah Sarfo Linda * and Asamoah Florence (2013). The attitudes of student nurses toward clinical work. Presbyterian University College of Ghana Asante-Akyem, Ghana

[3]. Bernhardt . JM. (2004) communication at the core of public health. American Journal of public health 94 (12): 2051 - 2052, December 2004.

[4]. Dyson (1997) in Monica E. Björkström MSc RNT ${ }^{1}$, Inger S. Johansson PhD RNT ${ }^{2}$, Elisabeth K. F. Hamrin $\mathrm{BM} \mathrm{PhD} \mathrm{RN}{ }^{3}$ and Elsy E. Athlin PhD RNT (2003) Swedish nursing students' attitudes to and awareness of research and development within nursing

[5]. Fineout -overholt, Ellen PhD, RN, FNAP, FAAN; Gallagher-Ford, Lynn PhD, RN: Kaplan, Louise PhD, RN, ARNP, FNP-BC, FAANP. JONA: September 2012 The Evidence for Evidence-Based Practice

[6]. Gallagher-Ford, Lynn PhD, RN; Kaplan, Louise PhD, RN, ARNP $29^{\text {th }}$ august 2012

[7]. Lynn MR, Laymun EL, Englebardt SP. (1998) Nursing administration research priorities: a national Delphi study. JONA 1998; 28: 7-11

[8]. Melnyk, Bernadette Mazurek PhD, RN, CPNP/PMHNP, FNAP, FAAN; Fineout-Overholt, Ellen PhD, RN, FNAP, FAAN; Gallagher-Ford, Lynn PhD, RN; Kaplan, Louise PhD, RN, ARNP, FNP-BC, FAANP (2008) The State of Evidence-Based Practice in US Nurses: Critical Implications for Nurse Leaders and Educators

[9]. Miley, K.K., O’Melia, M., \& DuBois, B.L. (2007): Generalist social work practice: An empowering approach .Boston: Allyn \& Bacon.

[10]. National cancer institute (2001); Making health communication programs work; Office of cancer communication. A planner guide (revised December 2001) NH Pub. No. 02-5145, 2002.

[11]. Polit and Beck (2006) Essentials of nursing research, methods, appraisal \& utilization, $6^{\text {th }}$ edition; Wilkins \& Wilkins Philadelphia.

[12]. Poster EC, Betz CL, Randel B. (1992) Psychiatric nurse's attitudes toward and involvement in nursing research. Journal of Psychosocial Nursing 1992; 30: 26-29.

[13]. Royal college of nursing Scotland.

[14]. Siemens D.R, Punnen S., Wong J., Kanji N. (2010): A survey on the attitude towards research in medical school. BMC Med.educ.10 (2010) p.4

[15]. Singchungchai Petchnoy Prof. / DR \& Chatermwanapong Salee Prof., Factors Influencing Research Experience among Professional Nurses in the Southern Regional Hospitals of Thailand. Faculty of Nursing, Prince of Songkla University, Songkhla, Thailand.

[16]. Srisuphan W. (1996): Research for development of nursing practice. Report on Direction in Nursing Practice in the Changing Period. Songkhla: Faculty of Nursing, Prince of Songkla University (Mimeograph in Thailand) 